\title{
STEREORADIOGRAPHY AS A PROMISING METHOD OF INTRAOPERATIVE NAVIGATION IN SPINE SURGERY
}

\author{
Guliaev D.A. ${ }^{1,2,3}$, Godanjuk D.S. ${ }^{1,2,3}$, Kondjukov D.A., ${ }^{2,3}$, Ivanov D.S. ${ }^{1}$, Biragov D.V. ${ }^{1}$, \\ Nazaruk V.P. ${ }^{4}$
}

${ }^{1}$ V.A. Almazov NMRC, Saint Petersburg, e-mail: spb.gda@yandex.ru;

${ }^{2}$ Clinical Hospital №122 named. L.G. Sokolov, Saint Petersburg, e-mail: godanyuk@gmail.com;

${ }^{3}$ Neurosurgical center named after prof. G.S. Tigliev, Saint Petersburg, e-mail: kondukov75@mail.ru;

${ }^{4}$ City Hospital No. 17, Saint Petersburg, e-mail: viktor-n63@mail.ru

Aims.

The study was aimed at the assessment of feasibility of the clinical use of stereoradiographic navigation for implantation of spine stabilising systems.

Materials and methods.

A stereoradiographic method is proposed for assessing the volume characteristics of structures with complex geometry, with summation of images of multiple objects. The X-ray parallax effect is used, which enables obtaining three-dimensional images after the hardware computer processing. Five patients received decompressive-stabilising operations to the extent of flavectomy, foraminotomy, transpedicular fixation and interbody stabilisation (TLIF). In the course of surgery, the conventional X-ray control as a stage of obtaining stereoscopic images, and stereoscopic navigation were used sequentially.

Results.

The authors demonstrated the feasibility of high-quality intraoperative visualisation of the main anatomical landmarks used in transpedicular implantation without increasing the radiation dose and surgery duration. Methodological principles and techniques that improve the quality of stereoradiographic images were provided.

Conclusions.

The efficacy of stereoradiography in stabilisation operations at all regions of the spine was demonstrated, including $X$-ray shielded regions of the inferior cervical and thoracic vertebra.

Keywords: X-ray control, intraoperative navigation, stereoradiography, X-ray stereo effect, spinal surgery, spondylolisthesis, transpedicular fixation.

\section{INTRODUCTION.}

X-ray images are widely used in spinal surgery for intraoperative navigation and control [1]. The method is affordable, familiar, and easy to use [2]. State-of-the-art equipment can adequately visualize the anatomical "landmarks" of the thoracic and lumbar spine, i.e. the sites used for implanting stabilizing transpedicular structures. At the same time, the use of X-ray images for intraoperative control is limited by the complexity of anatomy, as well as by the shielding effects of adjacent anatomical regions, especially in the lower cervical or upper thoracic spine [3-5]. Difficulties may arise when taking the volumetric measurements on flat X-ray scans, which is especially challenging for novice surgeons or when the spine is deformed [5]. Various intraoperative computer navigation methods have been proposed and are in use today to improve the outcomes of spinal surgery $[1 ; 2 ; 6-8]$. However, despite implantation being quite accurate even in the context of altered and complex anatomy, both methods have disadvantages pertaining to the duration and difficulty of preoperative planning, to the errors of adapting the method to the patientspecific anatomy; besides, the methods require advanced and rather expensive equipment [9-12].

Stereo X-ray imaging and navigation have earlier been tested for percutaneous transhepatic cholangiography [13]. The method generates a 3D X-ray image using a standard X-ray set. The algorithm is as follows: to record the first X-ray image (the baseline); to take the second image, to 
rotate the C-arm by 4 to 5 degrees. The X-ray images are software-processed and shown on a special stereo display or using stereo glasses; alternatively, anaglyph images (a red one and a blue one) can be generated for viewing through anaglyph glasses [14; 15]. The automatic recording and display of a stereo X-ray image take 0.5 seconds at max.

This paper dwells upon the preliminary results of testing stereo X-ray intraoperative navigation clinically when used for spinal surgery.

Goals and Objectives. The goal hereof is to test the feasibility of using stereo X-ray intraoperative navigation in spinal surgery in a clinical setting. The objectives are:

1. To find the optimal conditions of using stereo X-ray navigation for various spinal regions.

2. To compare the visualization parameters of the main X-ray landmarks, the radiation load and the duration of the study under standard and stereo X-ray navigation.

3. To test the feasibility of using stereo X-ray navigation for transpedicular implantation.

MATERIALS AND METHODS. This study was done in two stages: the anatomical stage and the clinical stage. Anatomical preparations of cervical and thoracic vertebrae were used to model transpedicular screw tracks by means of needles; the research team assessed the possibility of visualizing the main X-ray landmarks that are used to insert the transpedicular screws. Cadaverous material was used for transpedicular insertion of screws into cervical, thoracic, and lumbar vertebrae. Visualization parameters were comparatively analyzed for the medial and lateral pedicle walls, superior and inferior endplates, and the anterior body surface; it was checked whether and how efficiently the anatomical landmarks could be compared volume-wise. The research team evaluated the quality and informative value of stereo X-ray images generated at different longitudinal and transverse X-ray emitter displacements, as well as at different emitter-to-specimen distances.

The method was tested clinically when performing surgery on five patients treated against degenerative spondylolisthesis with lumbar instability. Patients were aged 63 on average, including 3 women and 2 men, none with severe somatic pathology.

The study protocol followed guidelines for experimental investigation with human subjects in accordance with the Declaration of Helsinki and was approved by the ethics committee. Written informed consent was obtained from each patient (or official representative) before the study.

The patient model was selected based on the relatively large size of lumbar vertebrae coupled with the implantation technique being rather independent from the navigation system in use. Every patient underwent stabilizing decompression surgery: flavectomy, foraminotomy, transpedicular fixation, and TLIF. The surgeons used standard X-ray imaging to generate stereo images, which were further used for stereo navigation. Figure 1 shows a surgeon's workplace used for such examination. 

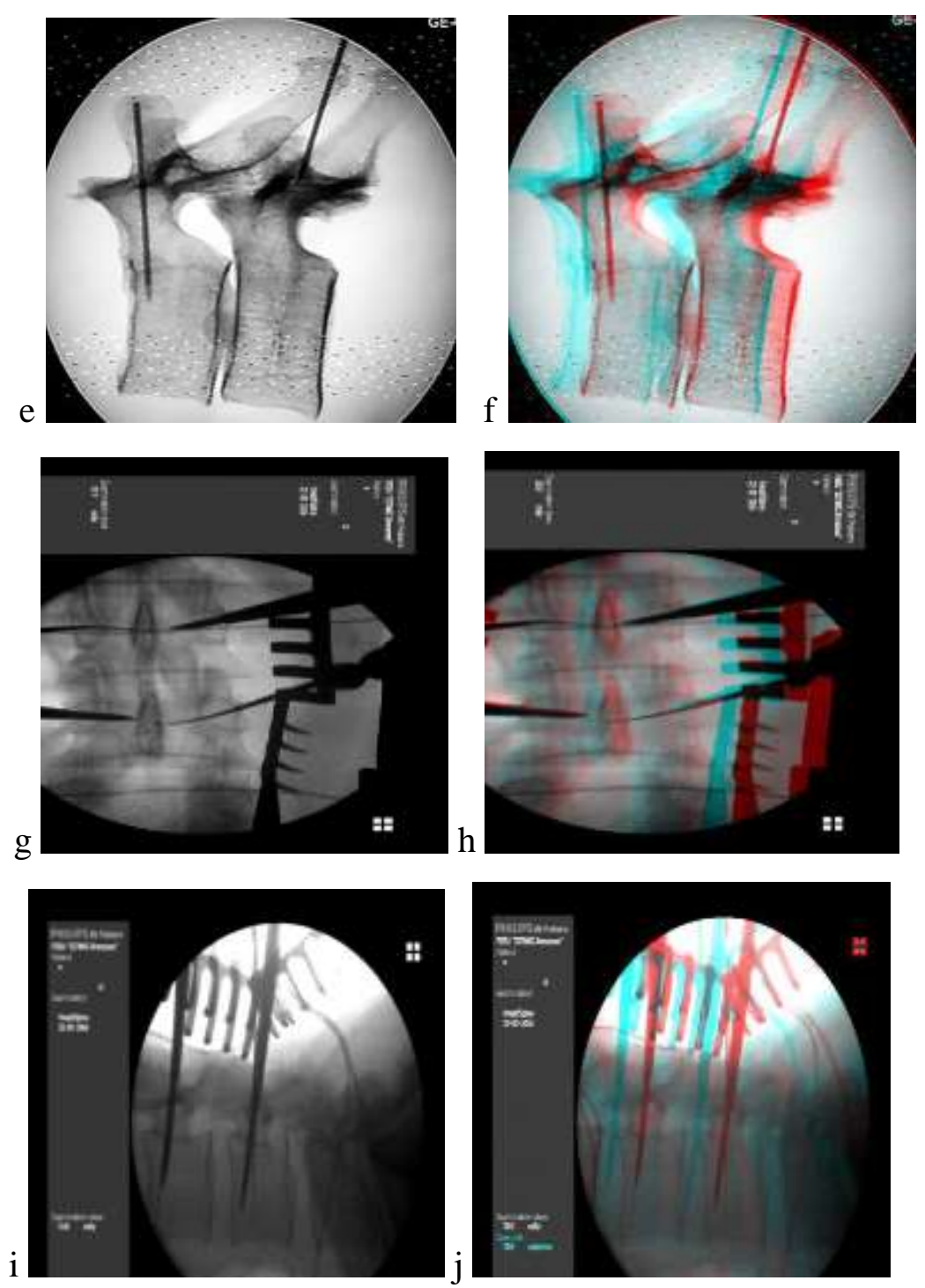

Figure 2. Comparison of key anatomical structure imaging: standard single-view images vs stereo X-ray images. Transpedicular screws tracks modeled in the anatomical preparations of cervical $(a, b)$, thoracic $(c, d, e, f)$, and lumbar $(g, h, i, j)$ vertebrae. Standard single-view $X$-ray images to the left, stereo $X$-ray anaglyph images to the right

The surgeons were asked to help optimize the visualization of the anatomical landmarks when using stereo X-rays as compared to standard single-view X-rays. Expert assessment used "yes or no" questions ( \pm in the Table) for a variety of conditions for different spinal segments, see Table. 
Visualization of anatomical landmarks in standard and stereo X-

rays: expert assessment

\begin{tabular}{|l|c|c|c|c|}
\hline \multirow{2}{*}{ Anatomical landmark } & \multicolumn{2}{|c|}{$\begin{array}{c}\text { Standard } \\
\text { X-rays }\end{array}$} & \multicolumn{2}{c|}{ images } \\
\cline { 2 - 5 } & $\begin{array}{c}\text { Frontal } \\
\text { view }\end{array}$ & $\begin{array}{c}\text { Lateral } \\
\text { view }\end{array}$ & $\begin{array}{c}\text { Frontal } \\
\text { view }\end{array}$ & $\begin{array}{c}\text { Lateral } \\
\text { view }\end{array}$ \\
\hline Medial pedicle wall & + & - & + & +- \\
\hline Inferior pedicle wall & + & + & + & + \\
\hline Superior endplate & + & + & + & + \\
\hline Inferior endplate & + & + & + & + \\
\hline Posterior surface of the vertebral body & - & +- & +- & + \\
\hline Anterior surface of the vertebral body & - & + & + & + \\
\hline
\end{tabular}

Thus, the research identified recommendable emitter-to-specimen (a patient's spine) distances as well as optimal $\mathrm{C}$-arm displacements (angles), at which best 3D images could be obtained. The emitter-to-specimen distance should be at least 35 to $40 \mathrm{~cm}$. For the second image, the emitter should be displaced by approximately 5 to $10 \mathrm{~cm}$. The $\mathrm{C}$-arm should be at an angle of 5 to 15 degrees with respect to the specimen. The stereo effect was weaker at shorter distances, as the stereo X-ray image became shallow. At greater X-ray emitter displacement, the human vision failed to merge two simple images into a 3D image. The arch root can be 3D-visualized in cervical and lumbar vertebrae by displacing the emitter in the axial plane; for thoracic vertebrae, sagittal displacement is the best, see Figures 2 and 3.

Using contrasts to mark the areas in front of and behind the specimen improves the perception of depth in 3D X-rays. These can be special contrasts for radiography or makeshift contrasts: wound retractors, wires, or leads, see Figure 3. 

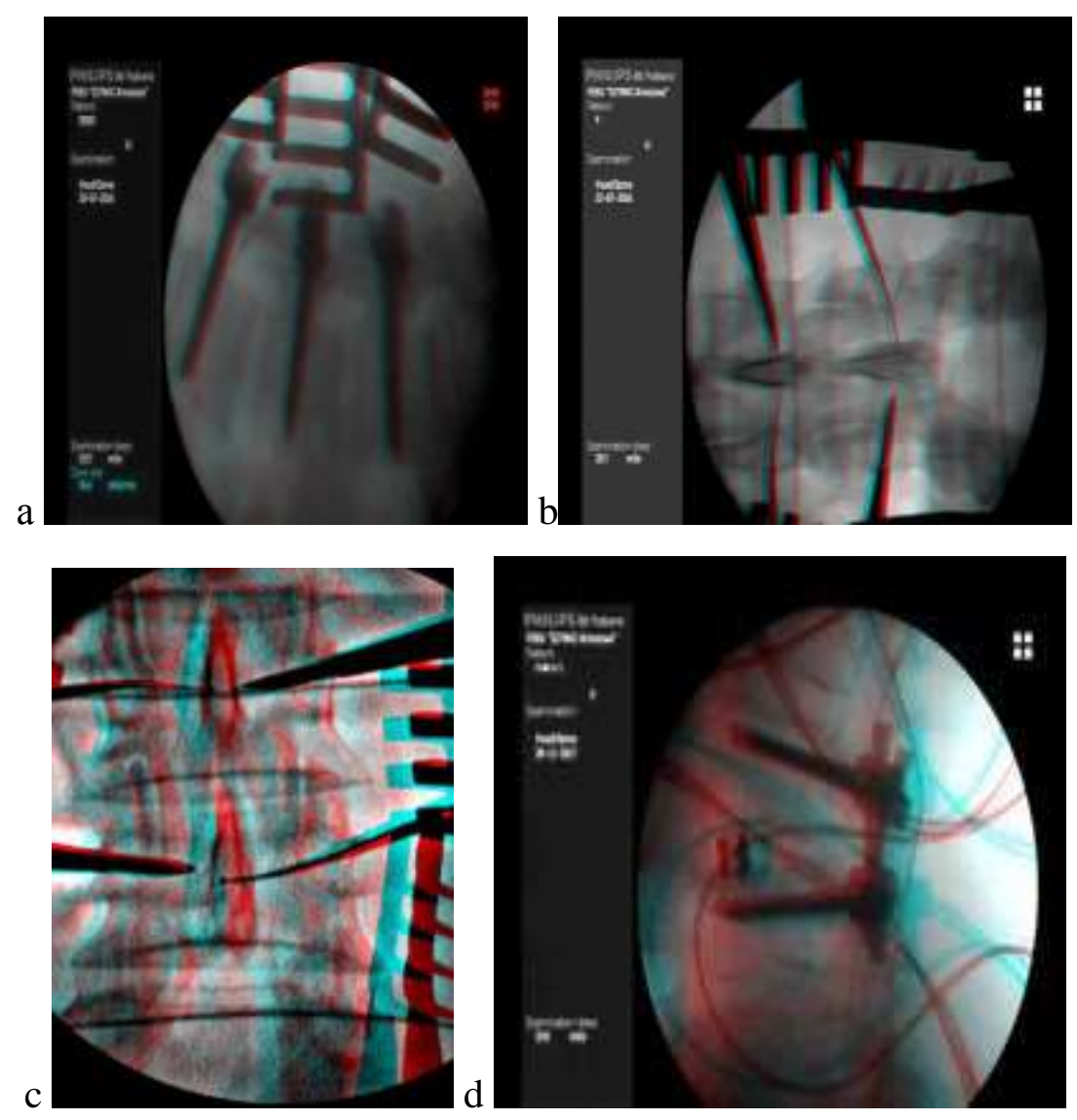

Figure 3. Visual markers:

$a, b$ are wound retractors; $c, d$ are dilators and radiological contrasts (wires)

Standard intraoperative X-ray imaging involves frontal and lateral radiography; at least two images are taken: $0.8+1.0 \mathrm{mSv}$ for the frontal view, $1.8 \mathrm{mSv}$ for the lateral view. Stereo X-rays are generated from two consecutively taken images per view: $0.8 \times 2=1.6 \mathrm{mSv}$ for the frontal view; $1.0 \times 2=2 \mathrm{mSv}$ for the lateral view. Thus, the patient's exposure will be $1.8 \mathrm{mSv}$ on average, which is not significantly different from the standard direct + lateral imaging. Stereo X-ray navigation enabled the surgeons to compare vertebral elements volume-wise and to implant the screws after a single radiographic examination, which resulted in lesser exposure, as less X-rays had to be taken per surgery.

Standard X-ray examination takes time to take two images, then to switch the C-arm from the frontal position to the lateral one, then switch it back; thus, a standard procedure would take 40 to 80 seconds. A stereo X-ray image requires two consecutively taken images; on the other hand, the X-ray tube needs not to be moved considerably. Together with computer processing, stereo Xray imaging takes 20 to 40 seconds, i.e. only about half the standard procedure time.

CONCLUSIONS. This research has effectively proven stereo X-ray imaging feasible for transpedicular implantation. Single-view 3D images provide an adequate view of all anatomical landmarks that the surgeon can compare in volume, including the contrasted lower cervical and upper thoracic vertebrae.

Experiments conducted as part of the study helped find out the optimal settings for different 
segments of the spine. The frontal view is the most optimal option for stereo X-ray imaging; the tube displacement is adjusted to the tilt of the arch root with respect to the vertebral body.

Stereo X-ray imaging was also associated with shorter procedure duration and lesser exposure, as less images had to be taken, especially in cases of altered or complex anatomy.

The proposed method can be effectively used for stabilizing surgery in any spinal segment.

\section{FINANCIAL SUPPORT AND SPONSORSHIP \\ Nil.}

\section{CONFLICTS OF INTEREST}

The authors declare no conflict of interest

SUPPLEMENTARY DATA (DOI)

\section{REFERENCES}

1. Houten J.K., Nasser R., Baxi N. Clinical assessment of percutaneous lumbar pedicle screw placement using the O-arm multidimensional surgical imaging system. Neurosurgery, 2012, vol. 70, no 4, pp. 990-995, doi 10.1227/neu.0b013e318237a829.

2. Phila P. Intraoperative spinal navigation. Spine, 2003, vol. 1, no 28, Suppl. 15, pp. 54-61.

3. Holly L.T., Foley K.T. Shoulder traction device for enhanced conventional fluoroscopy during cervical spine operations. Neurologia medico-chirurgica, 2013, vol. 53, no 2, p. 82-84, doi 10.2176/nmc.53.82.

4. Marangoz A., Cokluk C., Kuruoglu E. et al. A novel device to simplify intraoperative radiographic visualization of the cervical spine by producing transient caudal shoulder displacement: a 2-center case series of 80 patients. Journal of Neurosurgery Spine, 2013, vol. 19, no 6, pp. 697- 700, doi 10.3171/2013.9.spine11998.

5. Witiw C.D., Citow J.S., Ginsberg H.J. et al. Retrospective computed tomography scan analysis of percutaneously inserted pedicle screws for posterior transpedicular stabilization of the thoracic and lumbar spine: accuracy and complication rates. Spine, 2012, vol. 37, no 12, p. 1092-1100, doi 10.1097/brs.0b013e31823c80d8.

6. Bourgeois A.C., Faulkner A.R., Pasciak A.S. et al. The evolution of image-guided lumbosacral spine surgery. Annals of Translational Medicine, 2015, vol. 3, no 5, p. 69, doi 10.3978/j.issn.23055839.2015.02.01.

7. Raley D.A., Mobbs R.J. Evaluation of Screw Placement Accuracy in Circumferential Lumbar Arthrodesis Using Robotic Assistance and Intraoperative Flat-Panel Computed Tomography Author links open overlay panel. World Neurosurgery, 2017, vol. 105, pp. 86-94, doi 10.1016/j.wneu.2017.05.118.

8. Van de Kelft E., Costa F., Van der Planken D. et al. A prospective multicenter registry on the accuracy of pedicle screw placement in the thoracic, lumbar, and sacral levels with the use of the O- 
arm imaging system and stealthstation navigation. Spine, 2012, vol. 37, no 25, pp. 1580-1587, doi 10.1097/brs.0b013e318271b1fa

9. Kim T.T., Drazin D., Shweikeh F. et al. Clinical and radiographic outcomes of minimally invasive percutaneous pedicle screw placement with intraoperative CT (O-arm) image guidance navigation. Neurosurgical Focus, 2014, vol. 36, no. 3, p. e 1, doi 10.3171/2014.1.focus13531

10. Drazin D., Kim T.T., Polly Jr. D.W. et al. Introduction: intraoperative spinal imaging and navigation. Neurosurgical Focus, 2014, vol. 36, no. 3, doi 10.3171/2014.1.focus1425.

11. Park P., Foley K.T., Cowan J.A. et al. Minimally invasive pedicle screw fixation utilizing O-arm fluoroscopy with computer-assisted navigation: Feasibility, technique, and preliminary results. Surgical Neurology International, 2010, vol. 1, p. 44, doi 10.4103/2152-7806.68705.

12. Isik C., Kose K.C., Inanmaz M.E. et al. The mechanisms of medial pedicle wall violation: insertion method is as important as correct cannulation of the pedicle. Advances in Orthopedics, 2014, vol. 2014., pp. 1-5, doi 10.1155/2014/283783.

13. Nechaev A.I., Nazaruk V.P. Method for obtaining three-dimensional x-ray images. Patent of the Russian Federation [Sposob polucheniia trekhmernykh rentgenovskikh izobrazhenii. Patent Rossiiskoi Federatsii], № 2298887, 12.04.2004.

14. Melkonian A.B. Transdermal cholangiography: a teaching manual [Chreskozhnochrespechenochnaia kholangiografiia: uchebno-metodicheskoe posobie], St. Petersburg, Izd-vo TsNIOKI TsPI, 2004, 44 p.

15. Nechaev A.I., Nazaruk V.P., Chernakova S.E. Method of Three- Dimensional X-ray Image Acquisition and Visualization in a Real Time Mode for Nondestructive Testing and Medical Diagnostics [Metod registratsii i vizualizatsii trekhmernykh rentgenovskikh izobrazhenii v rezhime real'nogo vremeni dlia zadach nerazrushaiushchego kontrolia i meditsinskoi diagnostiki]. Information Technologies - Informatsionnye tekhnologii, 2005, no. 11, pp. 11-21. 